\title{
Study on Dynamic Variation Regularities of Regional Groundwater Depth Based on Complexity Diagnosis
}

\author{
Dong Liu*, Miao Yu, Nan Sun, and Ying Qi \\ School of Water Conservancy \& Civil Engineering, \\ Northeast Agricultural University, \\ Harbin Heilongjiang 150030, China \\ liu72dong@126.com
}

\begin{abstract}
In the course of analyzing and forecasting regional groundwater depth, its variation process complexity was ignored in the past, so that it was difficult to realize scientific management of groundwater resources. Aiming at the aforesaid defect, taking Jiansanjiang branch bureau as research platform, this paper diagnosed the complexity of each monthly groundwater depth series through using complexity measurement methods which include wavelet theory, fractal theory, Approximate Entropy and so on. The comprehensive measurement analysis results show that the complexity order of monthly groundwater depth series in the eighth district of Farm Nongjiang is highest in four farms of northern region. On that basis, the most complexity groundwater depth series combination stochastic forecasting model based on wavelet transform in northern region of Jiansanjiang branch bureau was set up. The model forecasting results show that local annual mean groundwater depth will be in a state of fluctuant lifting, and have considerable gap in comparison to groundwater ideal depth in the future. So, local government should reinforce the scientific management of groundwater. The research achievements break through the traditional study paradigm of hydrological forecasting, provide a research mode for studying regional hydrologic process, and provide scientific evidence for sustainable utilizing regional groundwater resources.
\end{abstract}

Keywords: northern region of Jiansanjiang branch bureau, groundwater depth, complexity diagnosis, wavelet transform, combination stochastic forecasting model.

\section{$1 \quad$ Introduction}

Groundwater is an important basic strategy resource to support the economic sustainable development of the regional society. Groundwater resources is a complex system [1], containing system factor such as water level, water quality, water quantity and water temperature etc., among which, groundwater level is the most sensitive and active one. Under conditions of unreasonable exploitation of groundwater, excessive

* Corresponding author. 
use of fertilizers and pesticides and some nature factors, fall of groundwater level, water quality deterioration and intensification of agricultural non-point source pollution etc. serious problem are induced, making the complexity of groundwater more and more clear which is general concerned by all circles. But the complexity of changing process was ignored by the domestic scholars when they studied the groundwater depth dynamic change regularity of the groundwater, resulting it imposable to fully excavate information of groundwater buried deeply change process and lack of practicality. Under this background, it is necessary to analyze predict the regional groundwater buried deeply series dynamic change to achieve the sustainable use of local groundwater, premised the complexity diagnoses.

Generally speaking, the higher complexity of the hydrological time series, the lower predictability of it[2]. So, to increase the prediction accuracy of the higher hydrological time series complexity, appropriate method should be chosen. Traditional prediction method of groundwater groundwater depth contains time series analysis[3], gray theory[4], artificial neural networks[5], multiple linear regression, seasonal decomposition model[6], self-memory model[7], etc., some of them base on linear theory, considered questions simply, some has ineffective extension, some has complex theories, these all resulting lower prediction accuracy or difficult to use. Wavelet analysis, developed recently, can demonstrate the fine structure series fully and extract change regularity easily of the hydrological time. The authors study the case of north district of Jiansanjiang branch bureau, to measure the complexity of the groundwater groundwater depth series to found the random predicting model of complex groundwater depth series of north district of Jiansanjiang branch bureau.

\section{Research Area and Methods}

\subsection{Research Area}

Heilongjiang Land Reclamation Jiansanjiang branch bureau is rice production base of China, locating at the junction of two cities and two countries of Fujin, Tongjiang, Raohe in Sanjiang Plain with the agricultural acreage of 682 thousand hm2[8] of total area of 12.3 thousand $\mathrm{km} 2[9]$. The north district of Jiansanjiang branch bureau includes farms of Qinglongshan, Qindeli, Nongjian and Yalu River with total land area of $2900.8 \mathrm{~km} 2$, and in the year of 2009 , the agricultural acreage is $147 \mathrm{hm} 2$. The district has provincial nature reserve of Qindeli sturgeon fish, Qinglonghe and Yalu River branch level nature reserve, mainly planted crops of rice, maize, soybean and wheat with higher mechanization and commodity grain. From 1920s, the district tied rice planting, and the acreage increased year by year, by the year of 2009, it was 105 thousand, taking up 71.4\% of the total agricultural acreage. Because of the lack of control projects, agriculture irrigation is mainly used groundwater, resulting continuous decline of the groundwater level. Meanwhile, under the influence of precipitation, evaporation and hydrological conditions, the complexity of the groundwater dynamic change become more and more clear of the district. Therefore, the authors try to 
analysis and predict the complex groundwater depth series dynamic change of the north district of Jiansanjiang branch bureau under the premise of complexity diagnose, to realize the sustainable use of the local groundwater resource.

\subsection{Data Sources}

From Heilongjiang Land Reclamation Jiansanjiang branch bureau Water Authority collected the monthly groundwater level series monitoring data including 15 farms practice of Jiansanjiang branch bureau from 1997 to 2007(n=132). Draw the groundwater level series changing curves of every areas in fig. 1.As can be seen from fig. 1, depth of the groundwater monitoring sites in Jiansanjiang branch bureau showed a gradual growth trend overall.

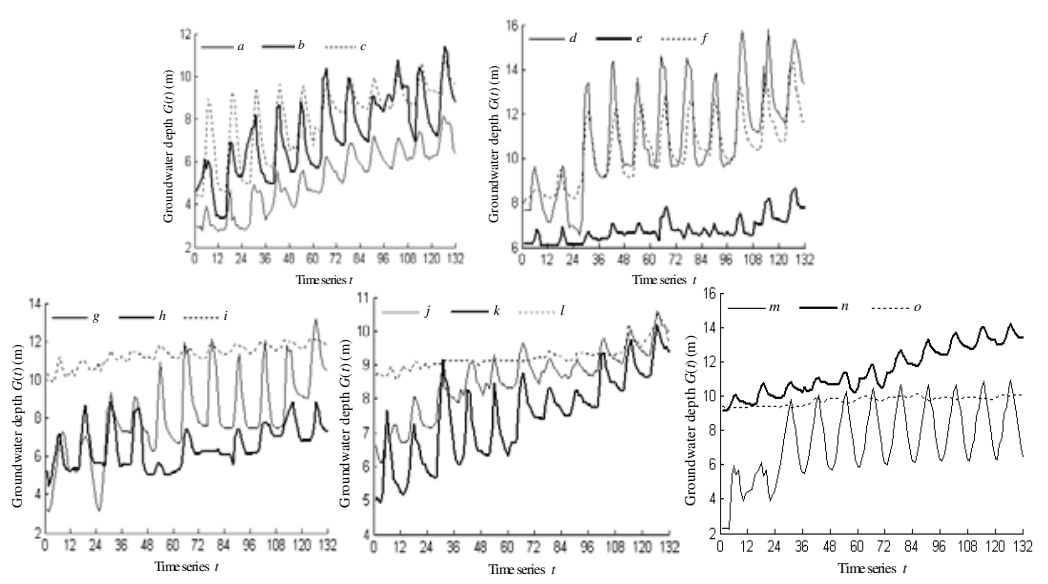

a. $1^{\text {st }}$ team of Farm 859; b. $69^{\text {th }}$ team of Farm Qixing; c. $22^{\text {nd }}$ team of Farm Qianjin; d.24 $4^{\text {th }}$ team of Farm Chuanye; e. $5^{\text {th }}$ team of Farm Yalu River; f. $28^{\text {th }}$ team of Farm Hongwei; g. $8^{\text {th }}$ district of Farm Nongjiang; h. $17^{\text {th }}$ team of Farm Qinglongshan; i.36 ${ }^{\text {th }}$ team of Farm Qindeli; j.main field of Farm Qianfeng; k. $6^{\text {th }}$ district of Farm Honghe; $1.5^{\text {th }}$ district of Farm Erdaohe; $\mathrm{m} .11^{\text {th }}$ team of Farm Daxing; n. $31^{\text {st }}$ team of Farm Shengli; o.12 $2^{\text {th }}$ team of Farm Qianshao

Fig. 1. Monthly groundwater level series changing curves of Jiansanjiang branch bureau (1997 2007)

\subsection{Diagnose Measurements of Hydrological Series Complexity}

Frequently used diagnose measurements of hydrological series contain information cost function based on wavelet transform(abbr. WT-ICF), approximate Entropy(abbr. $A p E n)$, Lempel-Ziv Complexity(abbr. $L Z C$ ), Resealed Range Analysis, (abbr. $R / S$ ), discrete wavelet transform(abbr. $D W T$ ), continue wavelet transform(abbr. $C W T$ ), etc., specific references as [10] and [11], not repeated here. 


\subsection{Modeling Principles of Hydrological Series Random Model Based on Wavelet Transform}

\subsubsection{Fast Wavelet Transform Method}

Computational complexity is big for information redundancy[12] of the obtained wavelet transform coefficient when the hydrological time series are wavelet transformed. So, fast wavelet transform (abbr. FWT) is usually used in practical application to calculate the wavelet transform coefficient. The authors use A Trous method [10] which is simple, fast and small computational complexity.

To wavelet transform the hydrological series $f(t)(t=1,2, \ldots, N)$, letting $C^{0}(t)$ $=f(t)$, the factorization and reconstruction process of $A$ Trous method is as following:

$$
\begin{gathered}
\left\{\begin{array}{l}
C^{j}(t)=\sum_{k=-\infty}^{+\infty} h(k) C^{j-1}\left(t+2^{j} k\right) \\
W^{j}(t)=C^{j-1}(t)-C^{j}(t)
\end{array}\right. \\
C^{0}(t)=C^{J}(t)+\sum_{j=1}^{J} W^{j}(t)
\end{gathered}
$$

Among which, $C^{j}(t), W^{j}(t)$ are the scale coefficient (background signal) and wavelet coefficient (detail signal) under $\mathrm{j}$ scale; $h(k)$ is discrete lowpass filter, generally be chosen the compactly supported symmetric third-order $B$-spline one, as $h(k)=(1 / 16,1 / 4,3 / 8,1 / 4,1 / 16) .\left\{W^{1}(t), W^{2}(t), \ldots, W^{j}(t), C^{j}(t)\right\}$ is called the wavelet transform series under $J$ scale.

\subsubsection{Modeling Procedures}

Wavelet transform method (e.g. A Trous Method) is used to transform the hydrological time series $f(t)$ to obtain wavelet transform series $\left\{W^{1}(t), W^{2}(t), \ldots, W^{J}(t), C^{J}(t)\right\}$ under some $J$ scale firstly, then recognize the main components (random or certain components ) of the wavelet transform series and found suitable mathematic models of each wavelet transform series, finally, to get the random predicting model ${ }^{[10]}$ of the studying hydrological time series $f(t)$ by the method of wavelet transform and reconstruction.

\section{$3 \quad$ Results and Analyses}

\subsection{Complexity Measures of Groundwater Level Series}

Estimated the complexity of each monthly groundwater depth series through using six kinds of complexity measurement methods mentioned above in Jiansanjiang branch bureau. The complexity diagnosis results of northern region of Jiansanjiang branch bureau shown in table 1 . 
Table 1. Calculated Results of the complexity index about monthly groundwater depth series in the northern region of Jiansanjiang branch bureau

\begin{tabular}{|c|c|c|c|c|c|c|c|c|c|c|c|c|c|c|}
\hline \multirow{5}{*}{$\begin{array}{l}\text { Long view } \\
\text { well } \\
\text { location }\end{array}$} & \multirow{3}{*}{\multicolumn{2}{|c|}{$\begin{array}{c}W T-I C F \\
(0.16)\end{array}$}} & \multirow{3}{*}{\multicolumn{2}{|c|}{$\begin{array}{l}\text { ApEn } \\
(0.16)\end{array}$}} & \multirow{3}{*}{\multicolumn{2}{|c|}{$\begin{array}{c}L Z C \\
(0.16)\end{array}$}} & \multicolumn{6}{|c|}{$D$} & \multirow{5}{*}{$\begin{array}{c}\text { comprehensi } \\
\text { ve } \\
\text { complexity } \\
\text { index }\end{array}$} & \multirow{5}{*}{$\begin{array}{c}\text { complexit } \\
\text { y sort }\end{array}$} \\
\hline & & & & & & & \multirow{2}{*}{\multicolumn{2}{|c|}{$\begin{array}{c}R / S \\
\text { Analysis } \\
(0.12)\end{array}$}} & \multicolumn{4}{|c|}{ Wavelet estimation } & & \\
\hline & & & & & & & & & \multicolumn{2}{|c|}{$\begin{array}{l}D W T \\
(0.16)\end{array}$} & \multicolumn{2}{|c|}{$\begin{array}{l}C W T \\
(0.24)\end{array}$} & & \\
\hline & sor & scor & sor & scor & sor & scor & sor & scor & sor & scor & sor & scor & & \\
\hline & $\mathrm{t}$ & $\mathrm{e}$ & $\mathrm{t}$ & $\mathrm{e}$ & $\mathrm{t}$ & $\mathrm{e}$ & $\mathrm{t}$ & $\mathrm{e}$ & $\mathrm{t}$ & $\mathrm{e}$ & $\mathrm{t}$ & $\mathrm{e}$ & & \\
\hline $17^{\text {th }}$ team of & & & & & & & & & & & & & & \\
\hline $\begin{array}{c}\text { Farm } \\
\text { Qinglongsha } \\
\mathrm{n}\end{array}$ & (8) & 8 & (8) & 8 & (3) & 13 & (1) & 15 & (10) & 6 & (6) & 10 & 9.80 & (3) \\
\hline $\begin{array}{c}36^{\text {th }} \text { team of } \\
\text { Farm } \\
\text { Qindeli }\end{array}$ & (5) & 11 & (10) & 6 & (2) & 14 & (9) & 7 & (13) & 3 & (15) & 1 & 6.52 & (11) \\
\hline $\begin{array}{c}8^{\text {th }} \text { district of } \\
\text { Farm }\end{array}$ & (7) & 9 & (12) & 4 & (7) & 9 & (5) & 11 & (2) & 14 & (1) & 15 & 10.68 & (2) \\
\hline $\begin{array}{l}\text { Nongjiang } \\
5^{\text {th }} \text { team of }\end{array}$ & & & & & & & & & & & & & & \\
\hline $\begin{array}{c}\text { Farm Yalu } \\
\text { River }\end{array}$ & (4) & 12 & (9) & 7 & (5) & 11 & (4) & 12 & (5) & 11 & (10) & 6 & 9.44 & (4) \\
\hline
\end{tabular}

Note: (1)The digital in parentheses is the weight of groundwater depth sequence complexity measurel;

(2) $\mathrm{D}$ is fractal dimension.

\subsection{Synthetical Complexity Measures of Groundwater Level Series}

In the above complexity measurement methods, Range Analysis is sensitive to the sequence length which is belongs to biased estimation and poor stability[13], while the method Continuous Wavelet Transform Fractal Theory has good stability[10] ,and others' be placed in the middle.In order to give full play to the advantages of various complexity measurement methods, according to the above analysis, determined the weight of that six complexity measures wi $(i=1,2, \ldots, 6)$ (shown in table 1). Assigned the corresponding score $s i=15 \sim 1$ to the sort result (1) (15)) of each monthly groundwater depth sequence complexity in Jiansanjiang branch bureau. Then get the groundwater depth sequence comprehensive complexity calculation formula:

$$
C_{l j}=\sum_{i=1}^{6} s_{i} w_{i}
$$

$C_{I j}$ is the comprehensive complexity index of which in the sort of $\mathrm{j}$ in groundwater depth sequence $, j=1,2, \ldots, 15$.

Calculate the comprehensive complexity index of groundwater depth sequence in northern region of Jiansanjiang branch bureau followed calculation formula (3), and the result seen in table 1.From table 1 we known that the synthetical complexity sort of 
northern region of Jiansanjiang branch bureau monthly groundwater level series is the eighth district of Farm Nongjiang $>$ the $17^{\text {th }}$ team of Farm Qinglongshan $>$ the fifth district of Farm Yalu River>the 36th team of Farm Qindeli>the $12^{\text {th }}$ team of Farm Qianshao.

\subsection{The Model of Complexity Groundwater Depth Series Combination Stochastic Forecasting Model Which Is Based on Wavelet Transform in Northern Region of Jiansanjiang Branch Bureau}

By the calculation analysis shows that the complexity of the eight district of Farm Nongjiang is the highest in the sort of five farms in northern region.Therefore, chose the monthly groundwater depth series of the eighth district of Farm Nongjiang as a representative, describe northern region of Jiansanjiang branch bureau groundwater depth dynamic change general characteristics based on analyzes dynamic change regulation above.Set up groundwater depth series combination stochastic forecasting model based on wavelet transform according to the monthly groundwater depth data surveied in the eighth district of Farm Nongjiang from 1997 to 2006. Reserved the data of 2007 as verify results.

(1) Wavelet decomposition and reconstruction of monthly groundwater depth series

Adopted A Trous algorithm mentioned above and boundary extension method which include 35 percent symmetric extension and the same proportion of linear extension and 30 percent orthogonal polynomials fitting extension to decompose the monthly groundwater depth series $G(t)(\mathrm{t}=1 \sim 120)$ of the eighth district of Farm Nongjiang from 1997 to 2006 through comparative analysis. The scale number $p=2$ here Obtained wavelet decomposition sequence $\left\{W^{l}(t), W^{2}(t), C^{2}(t)\right\}$, shown in fig. 2 (a),(b),(c).Then we can got reconstruction sequences by superposed every wavelet decomposition sequence.Shown in fig. 2(d).As can be seen from fig. 2(d), reconstruction complete agreement with the monthly groundwater depth series change precess results in fig.1.So, used ATrous algorithm to decompose monthly groundwater depth data series in the eighth district of Farm Nongjiang is feasible.
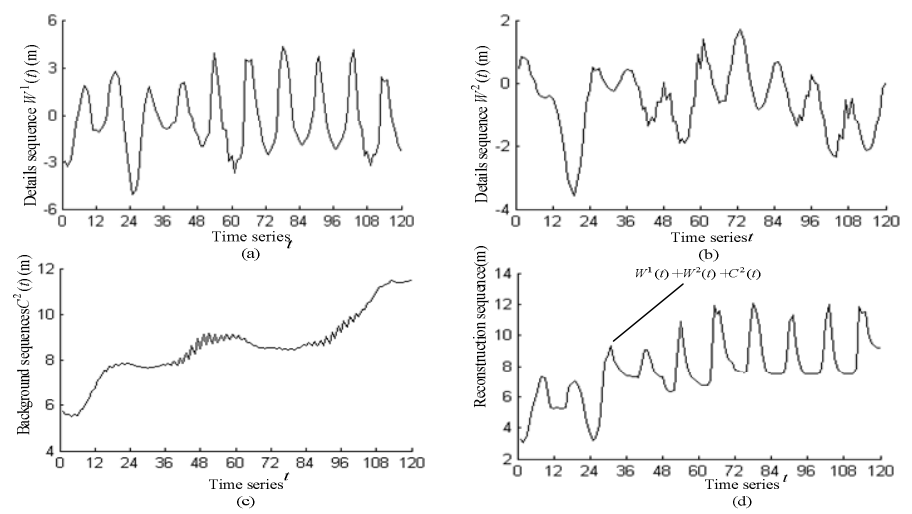

Fig. 2. Wavelet decomposition and reconstruction of monthly groundwater depth series in the eighth district of Farm Nongjiang 
(2) Component identification about wavelet transform sequence

Draw the self-relevant chart and variance spectral density fig. [14] of the wavelet transform sequence. Seen fig. 3 and fig. 4.

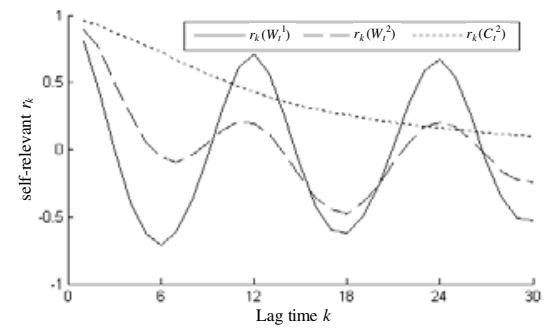

Fig. 3. The self-relevant charts of each wavelet transform series

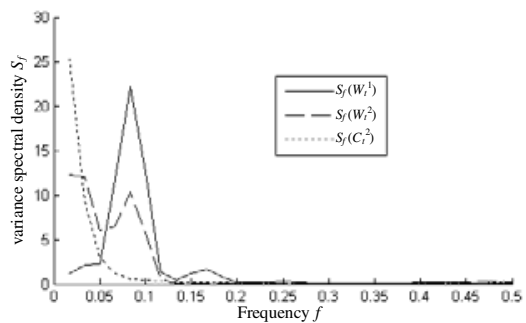

Fig. 4. The variance spectral density of each wavelet transform series

It can be seen from fig. 2, fig.3, fig. 4 that the wavelet decomposition sequence has a periodical for 12 months, and it has changing regularity powerful.So $W^{l}(t)$ which belongs to deterministic component can represent periodic term of $G(t)$.Although the wavelet transform sequence $W^{2}(t)$ also has a certain of periodicity that inferior to $W^{l}(t)$, it mainly reflect randomness. So we used $W^{2}(t)$ of which belongs to random component stand for randomness of $G(t)$. The sequence $C^{2}(t)$ not has periodic changing regularity but clear trend.For this reason, $C^{2}(t)$ which belongs to deterministic component [14]can be approximated as trend term of $G(t)$.

(3) Cross-correlation analysis about wavelet transform sequence

It can be seen each cross-correlation analysis curve [14] about wavelet transform sequence from fig. 5 .In this fig. $r_{k}\left(W^{1}, W^{2}\right), r_{k}\left(W 1, C^{2}\right)$, and $r_{k}\left(W,{ }^{2} C^{2}\right)$ showed the cross correlation coefficients among sequences $W^{1}(t), W^{2}(t)$, and $C^{2}(t)$ respectively. In addition, as the complex characteristics of original sequence is obvious, data sequences $W^{l}(t)$ and $W^{2}(t)$ are non stationary sequence with periodic or approximate periodic components, both part of the information contained overlap lead to many points in the cross correlation coefficient $r_{k}\left(W^{1}, W^{2}\right)$ beyond 95\% allows limited scope.So, Need to smooth with sequence $W^{l}(t)$ and $W^{2}(t)$.

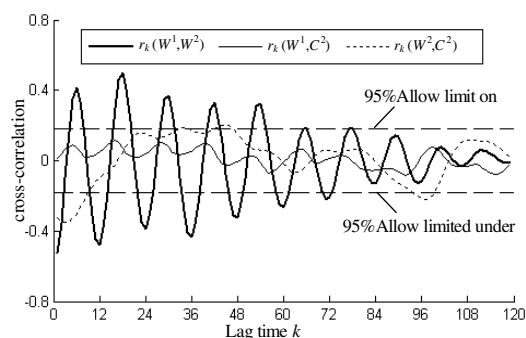

Fig. 5. The cross-correlation charts of each wavelet transform series

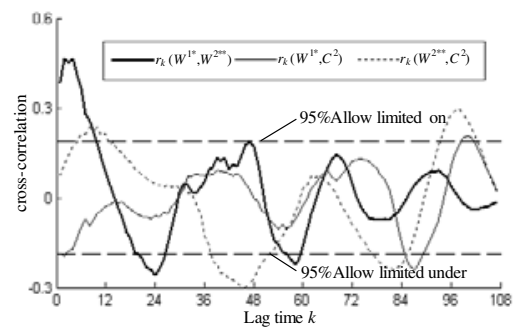

Fig. 6. The cross-correlation charts of each wavelet transform series after smooth processing 
(4) Smoothly with the wavelet transform $W^{l}(t)$ and $W^{2}(t)$

Take seasonal difference [15] to the series $W^{l}(t)$ who has 12 months (1 year) cycle of change rule obviously, will get the wavelet transform difference sequence $W^{l} *(t)$.For the sequences $W^{2}(t)$ also has 12 months (1 year) cycle of change rule obviously,and has nonstationarity remarkable.So,deal it with logarithmic transformation[16] method first of all ,obtain the logarithmic transformation series $W^{2} *(t)$. Then, take seasonal difference to $W^{2} *(t)$ to get the wavelet logarithmic transformation difference sequences $W^{2} * *(t)$.

(5)Cross-correlation analysis about wavelet transform sequence after smooth processing

Draw the cross-correlation curve about $W^{1} *(t), W^{2} * *(t)$ and $C^{2}(t)$ in fig. 6.It can be seen from the fig. that after smooth processing,the cross correlation coefficient are almost followed in $95 \%$ allows limited scope, and close to zero. Therefore, the mutual correlationof sequence is lesser.We can approximate think that they are independent of each other.The above cross-correlation analysis result showed that the components of $W^{1} *(t), W^{2} * *(t)$ and $C^{2}(t)$ nearly single ,more simple than $G(t)$. At the same time series $W^{1} *(t)$ and $W^{2 * *}(t)$ can be reduced to the wavelet sequences $W^{1}(t)$ and $W^{2}(t)$ after smooth processing. So analysis and deal with $\mathrm{G}(\mathrm{t})$ is means to manage $W^{1} *(t)$, $W^{2} * *(t)$ and $C^{2}(t)$

(6) Set up the combination stochastic model

From those analysis mentioned above, we known that sequence $W^{1} *(t)$ is got from periodic term $W^{l}(t)$ of original sequence after seasonal difference, and sequence $C^{2}(t)$ which belongs to deterministic component is approximate trend term of original sequence. At the same time, sequence $W^{2} * *(t)$ is got from stochastic $W^{2}(t)$ of original sequence after logarithmic transformation and seasonal difference, it belongs to stochastic component and it is approximate random component of original sequence. Therefore, set up auto-regression model[14] of $W^{1} *(t)$ and $C^{2}(t)$ (cut out random variables $\varepsilon_{t}$ ) and auto-regression model of $W^{2} * *(t)$ by using point of view of stochastic hydrology. Reduction and superposition each series' mathematical model then will got the groundwater depth series combination stochastic forecasting model which is based on wavelet transform in the eighth district of Farm Nongjiang

$$
\left\{\begin{aligned}
\hat{W}^{1^{*}}(t)= & 0.7216 W_{t-1}^{1^{*}}-0.2698 W_{t-12}^{1^{*}} \\
\hat{W}^{1}(t)=\hat{W}^{1^{*}}(t)+W^{1}(t-12) & \\
\hat{W}^{2 * *}(t)= & 0.0595+0.8300\left(W_{t-1}^{2^{* *}}-0.0595\right)+0.6934\left(W_{t-2}^{2 * *}-0.0595\right) \\
& \quad-0.8232\left(W_{t-3}^{2^{* *}}-0.0595\right)+0.3840\left(W_{t-5}^{2 * *}-0.0595\right)+\varepsilon_{\mathrm{t}} \\
\hat{W}^{2 *}(t)=\hat{W}^{2^{* *}}(t)+W^{2^{*}}(t-12) & \hat{W}^{2}(t)=2-e^{\hat{W}^{* *}(t)} \\
\hat{C}^{2}(t)= & 8.5940+0.8889\left(C_{t-1}^{2}-8.5940\right) \\
& +0.2438\left(C_{t-2}^{2}-8.5940\right)-0.2247\left(C_{t-3}^{2}-8.5940\right) \\
\hat{G}(t)= & \hat{W}^{1}(t)+\hat{W}^{2}(t)+\hat{C}^{2}(t)
\end{aligned}\right.
$$

Type with "^" said the corresponding sequence of predictive value 


\section{(7) Model fitting}

Adopted the most complexity groundwater depth series combination stochastic forecasting model which is based on wavelet transform to fit the monthly groundwater depth series in eighth district of Farm Nongjiang from 1997 to 2006. Shown in fig. 7. As can be seen from fig. 7, the model fitting effect is good.

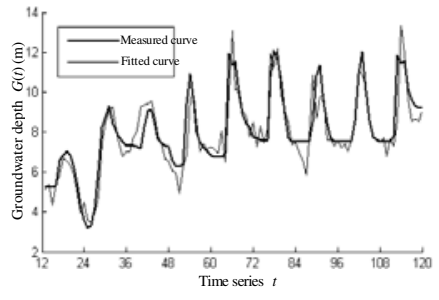

Fig. 7. The fitting curve of monthly groundwater depth series combination stochastic forecasting model in the eighth district of Farm Nongjiang (1997 2006)

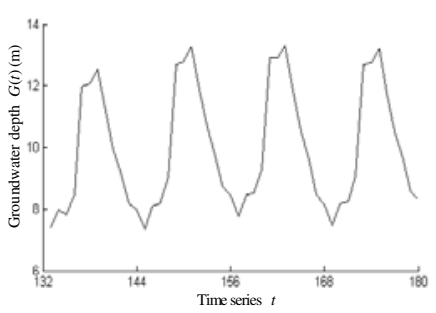

Fig. 8. The forecasting curve of monthly groundwater depth series combination stochastic forecasting model in the eighth district of Farm Nongjian (2008 2011)

\section{(8) Model Accuracy Test}

Used the data of most complexity groundwater depth series combination stochastic forecasting model which is based on wavelet transform to test the fitting effect, and used the left monthly modeling groundwater depth measurement data of 2007 which is not adopted in the model to test trial reported result. The specific results in Table 2.

Table 2. Accuracy test result of combination stochastic forecasting model based on wavelet transform

\begin{tabular}{|c|c|c|c|c|}
\hline \multicolumn{4}{|c|}{ Fitting Effect index } & \multirow{2}{*}{$\begin{array}{l}\text { Simulated } \\
\text { forecast index } \\
\text { E3 }(\%)\end{array}$} \\
\hline $\mathrm{C}$ & $\mathrm{p}$ & E1 $(\%)$ & E2 & \\
\hline 0.3208 & 0.9444 & 14.13 & 0.9259 & 83.33 \\
\hline
\end{tabular}

According to relevant literature we can see that posterior error ratio $\mathrm{C}$, fitting accuracy rate E2 and trial reported effect indexes E3 were reached I level standard, minimum error frequency $\mathrm{p}$ is II level, and the relative mean square error E1 reached III level standard [17]. Therefore, the model based on wavelet transform mentioned above have good fitting effect and highly forecast precision, can be used to predict future groundwater depth in the eighth district of Farm Nongjiang. 


\section{(9) Groundwater depth prediction}

Now adopted the most complexity groundwater depth series combination stochastic forecasting model which is based on wavelet transform to predict monthly groundwater level series of the eighth district of Farm Nongjiang from 2008 to 2011.The prediction data and prediction curve of groundwater table can be seen respectively in table 3 and fig. 8.From table 3 and fig. 8 shown that the groundwater level of the eighth district of Farm Nongjiang will fluctuate lift, if still using the past groundwater exploitation mode. The inter-annual luffing of groundwater level from 2008 to 2011 were $-1.28 \mathrm{~m}$, $0.52 \mathrm{~m}, 0.08 \mathrm{~m}$ and $-0.12 \mathrm{~m}$ respectively in the fluctuation change down-up-up-down state. And the groundwater level maintained at about $10 \mathrm{~m}$. This result have considerable gap in comparison to groundwater ideal depth which is about $4 \mathrm{~m}$ to $6 \mathrm{~m}$ in the future [18]. Therefore, the eighth district of Farm Nongjiang should increase groundwater management efforts, to protect local limited of groundwater resources.

Table 3. The prediction data of monthly groundwater depth in the eighth district of Farm Nongjiang (2008 2011) (m)

\begin{tabular}{ccccccccccccccc}
\hline Mear & 1 & 2 & 3 & 4 & 5 & 6 & 7 & 8 & 9 & 10 & 11 & 12 & Average \\
\hline 2008 & 7.4118 & 7.9645 & 7.8243 & 8.4863 & 11.9801 & 12.0779 & 12.5336 & 11.1655 & 9.9586 & 9.1503 & 8.1838 & 7.9454 & 9.56 \\
2009 & 7.3383 & 8.0817 & 8.1816 & 9.0356 & 12.6974 & 12.7893 & 13.2663 & 11.8944 & 10.6546 & 9.8109 & 8.7365 & 8.4515 & 10.08 \\
2010 & 7.7792 & 8.4760 & 8.5244 & 9.3032 & 12.9034 & 12.9148 & 13.3161 & 11.8589 & 10.5339 & 9.6153 & 8.4798 & 8.1595 & 10.16 \\
2011 & 7.4709 & 8.1710 & 8.2395 & 9.0524 & 12.6953 & 12.7523 & 13.2019 & 11.7968 & 10.5272 & 9.6653 & 8.5838 & 8.3112 & 10.04 \\
\hline
\end{tabular}

\section{Conclusions}

It is more obvious, driven in a variety of factors, the complexity of characteristics during the course of the regional groundwater table changed has became. So, it has broken the traditional hydrological forecasting patterns and has more practical significance for the regional groundwater resource management that analysis of groundwater depth development trend based on identify regional groundwater depth sequence complex. This paper diagnosed the complexity of 15 monthly groundwater level series through many kinds of data mining methods in Heilongjiang Agricultural Reclamation Jiansanjiang branch bureau. The complexity diagnosis results show that the complexity order of monthly groundwater depth series in the eighth district of Farm Nongjiang is highest in five farms of northern region. On that basis, the most complexity groundwater depth series combination stochastic forecasting model based on wavelet transform in northern region of Jiansanjiang branch bureau in the eighth district of Farm Nongjiang was set up. This model concepts are clear, structured and high reliability. The model forecasting results show that local annual mean groundwater depth will be keep $10 \mathrm{~m}$, and have considerable gap in comparison to groundwater ideal depth in the future. So, local government should reinforce the scientific management of groundwater. Need to point out is that The stability of the 
complexity measure results by certain effect as the groundwater depth monitoring data insufficient length in Jiansanjiang branch bureau. In the future, with the monitoring data accumulation, we should update this paper research.

Acknowledgments. Thanks to National Natural Science Foundation of China), No.41071053), China Postdoctoral Science Foundation (No.20080440832), China Postdoctoral Scientific Fund special funding (No.201003410), Research Fund for the Doctoral Program of Higher Education of China (No.20102325120009), Natural Science Foundation of Heilongjiang Province, China (No.C201026), Science and Technology Foundation of Education Department of Heilongjiang Province (No.11541024), Dr Start-up Fund Research of Northeast Agricultural University (No.2009RC37).

\section{References}

[1] Wang, G., Liang, G.: Application of Multi-period, Multi-level and Multi-objective Fuzzy Optimization Model in Groundwater System Management Decision-making. Journal of China Hydrological 29(6), 24-27 (2009)

[2] Peng, T., Chen, X., Zhuang, C.: Analysis on complexity of monthly runoff series based on sample entropy in the Dongjiang river. Ecology and Environmental Science 18(4), 1379-1382 (2009)

[3] Liu, D., Ma, Y.-S., Fu, Q.: Study on Dynamic Variation Regularities of Groundwater in Area of Well Irrigation Paddy in Sanjiang Plain. Journal of Irrigation and Drainage 25(5), 42-46 (2006)

[4] Zhang, W.-T., Sun, J.-Y., Wu, C.-Y.: Research on the application of groundwater dynamic change regulation based on the gray-theory in pingdu. Shandong Water Resources (3-4), 45-48 (2009)

[5] Banerjee, P., Prasad, R.K., Singh, V.S.: Forecasting of groundwater level in hard rock region using artificial neural network. Environmental Geolog 58(6), 1239-1246 (2009)

[6] Xu, Q., Shu, L., Yang, D., et al.: Model on Groundwater Level Dynamic Statistical in Pinggu Plain of Beijing. Water Resources and Power 27(5), 58-61 (2009)

[7] Li, R., Shen, B., Zhang, J.: Self-memory model for predicting groundwater depth series with periodical fluctuation. Transaction of The Chinese Society of Agricultural Engineering 21(7), 34-37 (2005)

[8] Zhao, Q.: Research on the Trend of Underground Water Change in Jiansanjiang Area Based on Gray Prediction. Journal of Water Resources and Water Engineering 20(5), 128-130, 134 (2009)

[9] Guo, L., Ma, K.-M., Zhang, Y.: Landscape assessment on wetland degradation during thirty years in Jiansanjiang region of Sanjiang Plain, Northeast China. Acta Ecologica Sinica 29(6), 3126-3135 (2009)

[10] Wang, W.-S., Ding, J., Li, Y.-Q.: Hydrological wavelet analysis. Chemical Industry Press, Beijing (2005)

[11] Tong, C.-S., Huang, Q., Liu, H., et al.: Study on runoff series complexity based on approximate entropy. Journal of Northwest Sci-Tech University of Agriculture and Forestry 33(6), 121-126 (2005)

[12] Ding, S.-Y.: Laplacian Pyramid image data compression based on wavelet transformation. Journal of Weifang University 9(4), 34-36 (2009) 
[13] Rakhshandehroo, G.R., Shaghaghian, M.R., Keshavarzi, A.R., et al.: Temporal variation of velocity components in a turbulent open channel flow: Identification of fractal dimensions. Applied Mathematical Modelling 33(10), 3815-3824 (2009)

[14] Ding, J., Liu, Q.-S.: Stochastic hydrology. China Water Power Press, Beijing (1997)

[15] Yu, Y.-H., Wang, J., Song, J.-D.: Research on traffic prediction and result analysis of using multiplicative seasonal autoregressive integrated moving average. Computer Engineering and Application 45(20), 99-102 (2009)

[16] Chen, D.-G., Hu, N.-L., Li, G.-Q.: Stationarity for the non-normal distribution of regionalized variables. Journal of University of Science and Technology Beijing 31(4), 412-417 (2009)

[17] Chen, N.-X.: Evaluating the Precision of Forecasting Model for Groundwater Dynamic. Geotichnical Investigation and Surveying 3, 35-38 (1999)

[18] Yuan, B., Du, S.-M., Yang, W.-Q., et al.: Status Overdraft of Groundwater on Sanjiang Plain(2). Journal of Heilongjiang Hydraulic Engineering College 35(1), 18-21 (2008) 